\title{
Quantification of myocardial stiffness in heart failure with preserved ejection fraction porcine model using magnetic resonance elastography
}

\author{
Ria Mazumder ${ }^{1,2^{*}}$, Samuel Schroeder ${ }^{3}$, Bradley D Clymer ${ }^{1}$, Richard D White ${ }^{2}$, Arunark Kolipaka ${ }^{2}$ \\ From 19th Annual SCMR Scientific Sessions \\ Los Angeles, CA, USA. 27-30 January 2016
}

\section{Background}

Heart failure with preserved ejection fraction ( $\mathrm{HF} p \mathrm{EF})$ is associated with a complex heterogeneous pathophysiology which is poorly understood thereby preventing appropriate diagnosis and prognosis ${ }^{1}$. However, it is known that most of the cardiovascular and non-cardiac abnormalities that induce $\mathrm{HF} p \mathrm{EF}$ are eventually manifested as an increase in left ventricular (LV) myocardial stiffness (MS). Therefore, we hypothesize that quantifying MS will assist in timely diagnosis of $\mathrm{HF} p \mathrm{EF}$ and reveal pathophysiological conditions that are specific to the prognosis of $\mathrm{HF} p \mathrm{EF}$. Recently, with the advent of cardiac magnetic resonance elastography (cMRE) it has been feasible to estimate the shear stiffness of myocardium noninvasively ${ }^{2}$. In this study, we use cMRE to estimate the change in LV MS across the cardiac cycle during disease progression in HF $p$ EF induced pigs.

\section{Methods}

Renal wrapping surgery was performed in 5 pigs to induce $\mathrm{HF}_{\mathrm{EF}} \mathrm{E}^{3}$. $\mathrm{cMRE}$ was performed at baseline $(\mathrm{Bx}$, prior to surgery), month 1 (M1) and month 2 (M2) on a 1.5T MRI scanner (Avanto, Siemens Healthcare, Erlangen, Germany). cMRE imaging parameters includes: TR/TE = $12.5 / 9.71 \mathrm{~ms} ;$ FOV $=384 \times 384 \mathrm{~mm}^{2}$; Resolution $=3 \times 3 \times$ $8 \mathrm{~mm}^{3}$; Flip angle $=15^{\circ}$; GRAPPA $=2$; Mechanical frequency $=80 \mathrm{~Hz}$; Encoding frequency $=160 \mathrm{~Hz}$; Phase offsets $=4$. Images were masked to extract the LV and estimate cMRE-derived LV MS across the cardiac cycle using 3D local frequency estimation inversion algorithm at each time point. End- systolic (ES) and diastolic (ED) MS were correlated to the corresponding ES and ED pressures obtained using LV catheterization.

EElectrical and Computer Engineering, The Ohio State University, Columbus, $\mathrm{OH}$, USA

Full list of author information is available at the end of the article

\section{Results}

Fig 1 demonstrates that cMRE-derived stiffness increases with disease progression from $\mathrm{Bx}$ to $\mathrm{M} 1$ to $\mathrm{M} 2$ throughout the cardiac cycle indicating that HF $p$ EF causes an elevation in LV MS. Furthermore, ES MS is significantly higher (p-value $<0.001$ ) than ED MS at all-time points. Fig 2 shows moderate correlation between ES and ED MS and corresponding pressure from LV catheterization with a $R^{2}$ value of 0.4 .

\section{Conclusions}

Our result demonstrates that cMRE-derived MS increases with disease progression in $\mathrm{HF} p \mathrm{EF}$ porcine

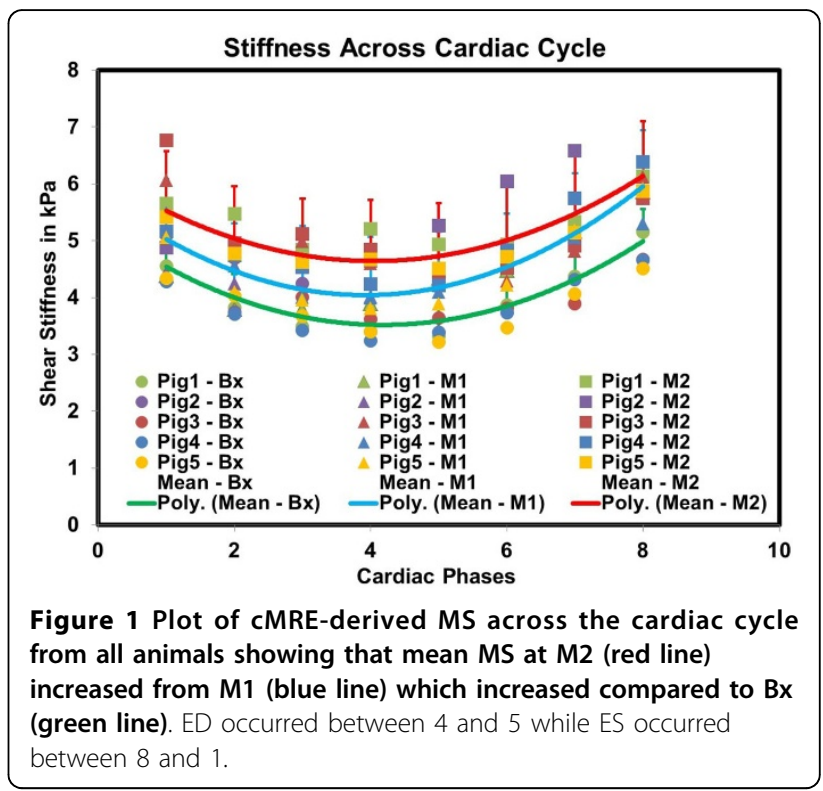




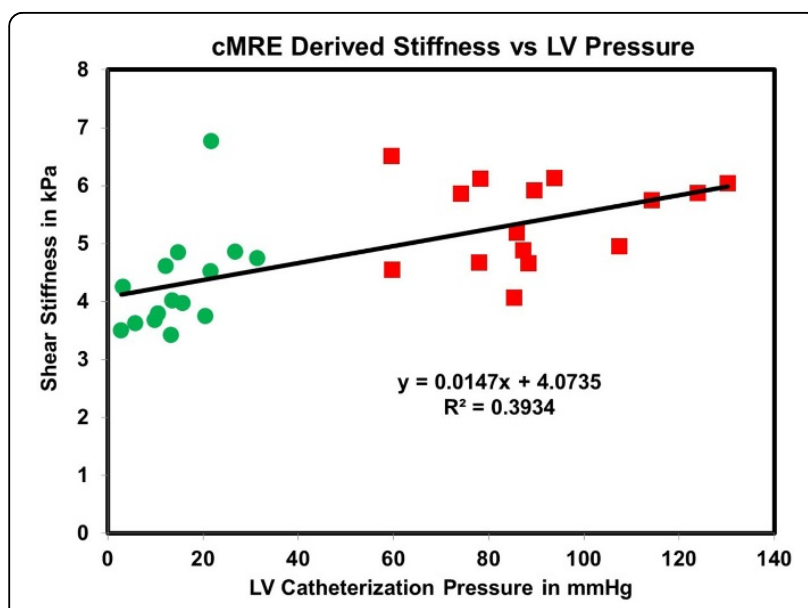

Figure 2 Graph shows correlation between CMRE-derived ES and ED MS vs catheter-based ES and ED LV pressure.

model thereby indicating the scope of using cMRE as a diagnostic tool to diagnose $\mathrm{HF} p \mathrm{EF}$ condition.

\section{Authors' details}

${ }^{1}$ Electrical and Computer Engineering, The Ohio State University, Columbus, $\mathrm{OH}$, USA. ${ }^{2}$ Department of Radiology, The Ohio State University, Columbus,

$\mathrm{OH}$, USA. ${ }^{3}$ Department of Mechanical Engineering, The Ohio State University, Columbus, OH, USA.

Published: 27 January 2016

\section{References}

1. Kitzman DW, et al: Journal of the American College of Cardiology 2014, 63(5): P30-459.

2. Wassenaar P, et al: Magnetic Resonance in Medicine 2015.

3. Grollman A: Proceedings of the Society for Experimental Biology and Medicine 1944, 57(1):102-104.

doi:10.1186/1532-429X-18-S1-P29

Cite this article as: Mazumder et al:: Quantification of myocardial stiffness in heart failure with preserved ejection fraction porcine model using magnetic resonance elastography. Journal of Cardiovascular Magnetic Resonance 2016 18(Suppl 1):P29.
Submit your next manuscript to BioMed Central and take full advantage of:

- Convenient online submission

- Thorough peer review

- No space constraints or color figure charges

- Immediate publication on acceptance

- Inclusion in PubMed, CAS, Scopus and Google Scholar

- Research which is freely available for redistribution

Submit your manuscript at www.biomedcentral.com/submit 